\title{
AVALIAÇÃO DA QUALIDADE DA ÁGUA DE ABASTECIMENTO EM CRECHES E ASILO DO MUNICÍPIO DE JOÃO MONLEVADE - MG
}

Maria Carmen Lopes Pereira - mariacarmenlp@ gmail.com

Universidade do Estado de Minas Gerais - Unidade de João Monlevade

Aniele Bessa Gualberto - bessa.aniele@ gmail.com

Universidade do Estado de Minas Gerais - Unidade de João Monlevade

Dra. Jaquelline Carla Valamiel de Oliveira e Silva -

jackvalamiel@yahoo.com.br

Universidade do Estado de Minas Gerais - Unidade de João Monlevade 


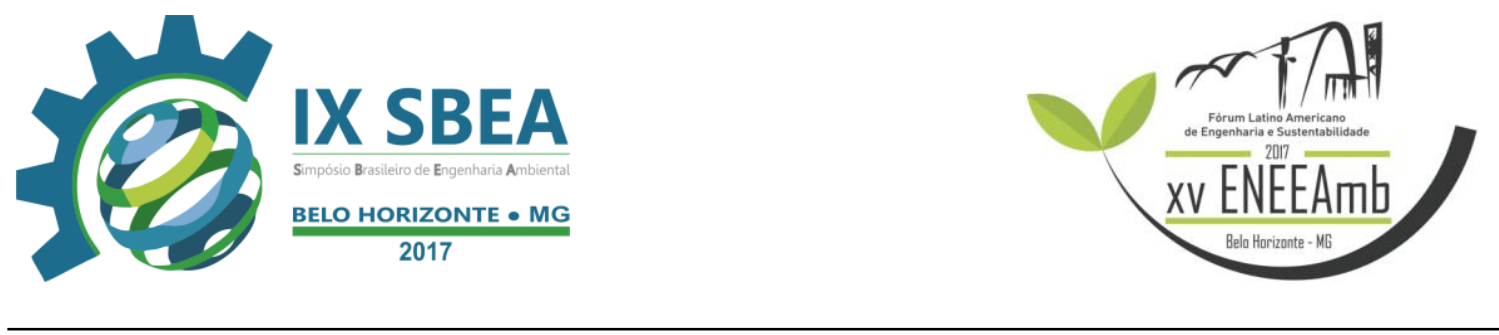

\section{RESUMO}

O presente estudo objetivou avaliar a qualidade da água para consumo humano em creches e asilo do município de João Monlevade, Minas Gerais. Foram selecionadas 09 instituições, das quais amostras de água foram coletadas e submetidas a análises físico-químicas ( $\mathrm{pH}$, turbidez e cloro residual livre) e microbiológicas (presença/ausência de coliformes totais e Escherichia coli, contagem de Unidades Formadoras de Colônias - UFC de bactérias heterotróficas em meio Ágar Nutriente, e coloração Gram). Para cada instituição foi coletada uma amostra de água em 03 pontos distintos: Ponto 1 (bebedouro), Ponto 2 (torneira da cozinha), e Ponto 0 (entrada da rede de água). As análises físico-químicas demonstraram que 08 instituições não atenderam a legislação, uma vez que apresentaram valores fora do padrão para concentração de cloro residual livre nos pontos depois da reservação (Pontos 1 e 2). As análises microbiológicas detectaram a presença de coliformes totais em 02 amostras, sendo elas no Ponto 1 das instituições B e D. A contagem de bactérias heterotróficas, demonstrou que nenhuma das amostras de água ultrapassou o limite permitido de até 500UFC/mL. Quanto ao teste da coloração Gram,42,3\% foram bactérias gram-negativas e 34,6\% gram-positivas.

Palavras-chave: Qualidade da água. Creches. Asilo. Parâmetros físico-químicos. Coliformes totais. E. coli.

\section{INTRODUÇÃO/OBJETIVO}

Segundo a Portaria № 2.914/11, do Ministério da Saúde, a água destinada ao consumo humano deve estar em consonância com os parâmetros de qualidade e padrão de potabilidade estabelecidos na legislação, e ser alvo de constante monitoramento, para a manutenção de sua qualidade. Um dos indicadores biológicos mais empregados no monitoramento da qualidade da água são as bactérias do grupo coliforme termotolerante, pois, quando presentes, indicam a contaminação das águas por fezes humana e/ou animal.

Considerando que idosos e crianças compõem os grupos mais susceptíveis à doenças de veiculação hídrica, o presente estudo se justifica no sentido de avaliar a 


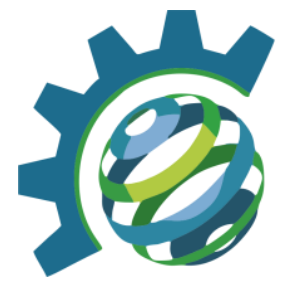

qualidade da água em asilo e creches, no intuito de verificar se a água consumida nesses locais atendem à legislação. Assim, este estudo se preocupa em monitorar a qualidade da água, em locais onde estes grupos de risco permanecem por um longo período do dia ou até mesmo estabelece moradia, como no caso dos asilos.

Sendo assim, o objetivo geral foi avaliar a qualidade da água de creches e asilo, localizados no município de João Monlevade, Minas Gerais, analisando os parâmetros físico-químicos $(\mathrm{pH}$, turbidez e cloro residual livre) e microbiológicos (coliformes totais, Escherichia coli, bactérias heterotróficas) das amostras de água, a fim de verificar se os mesmos atendem aos limites do padrão de potabilidade determinados na Portaria $\mathrm{N}^{\mathrm{o}} 2.914 / 11$, e se a água consumida nos locais em estudo apresenta risco para a saúde de seus frequentadores.

\section{METODOLOGIA}

\section{1 Área de estudo}

O estudo foi realizado no município de João Monlevade, situado na região central do estado de Minas Gerais, que no âmbito da educação infantil, possui 08 centros de educação pertencentes a rede municipal e 01 casa de repouso para idosos.

\subsection{Aplicação do questionário}

Foi aplicado um questionário com a autoridade local de cada instituição para a obtenção de dados relevantes para o estudo.

\subsection{Coleta de amostras de água}

As amostras de água foram coletadas no período do mês de novembro de 2016 em 08 centros de educação infantil e no asilo. Cada local recebeu um código; primeiramente uma letra para cada instituição, de "A" a "I", seguida dos números 1, 2 ou 0, que caracteriza os pontos de coleta: Ponto 1 - Bebedouro, Ponto 2 -Torneira da cozinha e Ponto 0 - Entrada da rede de água.

Foram coletadas amostras de água nos 03 pontos (1, 2 e 0$)$ de cada instituição, excepcionalmente, na instituição I, não foi possível realizar a coleta no Ponto 0 , pois a maior parte do seu abastecimento, é proveniente de um poço artesiano, o qual estava concretado e não permitia a coleta no ponto antes da reservação. Foram coletadas, no total, 26 amostras para análises físico-químicas e 26 amostras para análises 


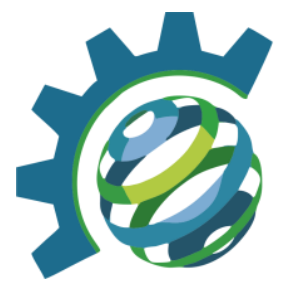

microbiológicas. Todas as torneiras foram limpas com álcool etílico a $70 \%$, posteriormente abertas durante 02 a 03 minutos. Foram coletadas em cada ponto amostras de $1 \mathrm{~L}$ de água para as análises físico-químicas e $200 \mathrm{~mL}$ para as análises microbiológicas. Todas as análises foram realizadas nos Laboratórios de Química e Biologia da Universidade do Estado de Minas Gerais, Unidade de João Monlevade MG.

\subsection{Determinação do $\mathrm{pH}$}

Para determinação do pH, utilizou-se o pHmetro Combo by HANNA devidamente calibrado com a faixa operacional estabelecida pelo fabricante.

\subsection{Determinação da turbidez}

A determinação da turbidez foi realizada com auxílio de um turbidímeto digital DM-TU Digimed, devidamente calibrado, de acordo com as instruções e faixas estabelecidas pelo fabricante.

\subsection{Determinação da concentração de cloro residual}

Para calcular a concentração de cloro residual, primeiramente calculou-se o número de mols (n) de $\mathrm{Cl}_{2}$, conforme expressão 01 .

$$
\mathrm{n}\left(\mathrm{Cl}_{2}\right)=\left(\mathrm{C} . \mathrm{V}_{\text {titulante }}\right) / 2
$$

Encontrado o número de mols, calculou-se a massa de cloro presente na amostra, em termos de gramas (g), conforme a expressão 02.

$\mathrm{n}\left(\mathrm{Cl}_{2}\right)=\mathrm{m} / \mathrm{MM}\left(\mathrm{Cl}_{2}\right)$

A partir da massa de cloro encontrada, fez-se a relação dessa massa, encontrada em 100mL da amostra, para o volume de 1L, achando-se assim, a concentração de cloro residual em termos de mg/L, conforme expressão 03.

Concentração $\left(\mathrm{Cl}_{2}\right)=(\mathrm{m} * 1000) / 0,1$

\subsection{Determinação da ausência/presença de coliformes totais e E.coli}




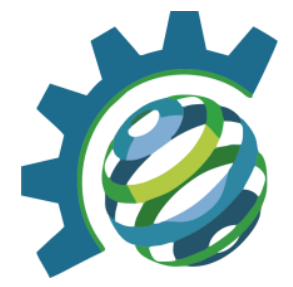

Para realização desta análise, utilizou-se recipientes plásticos novos, com capacidade para $140 \mathrm{~mL}$. Após serem irradiados com luz ultravioleta durante 20 minutos, foi adicionado a cada recipiente a quantidade de $100 \mathrm{~mL}$ de amostra de água e um blister do kit Colilert, IDEXX. Os recipientes foram fechados, levemente agitados e então armazenados em estufa bacteriológica DELEO, com temperatura de $35,0 \pm 0,5^{\circ} \mathrm{C}$, durante 24 horas. Decorridas as 24 horas da incubação, os frascos foram retirados da estufa para observação da mudança de coloração das amostras. A coloração amarelada é a confirmação do teste positivo para coliformes totais presentes na amostra. Os frascos que possuíam coloração amarela foram expostos a luz ultravioleta $365 \mathrm{~nm}$. A fluorescência azul obtida a partir desta exposição permite afirmar que há E.coli presente na amostra.

\subsection{Contagem de bactérias heterotróficas}

Para a contagem de bactérias heterotróficas, empregou-se a técnica de cultivo em profundidade, utilizando-se o meio de cultura Ágar Nutriente em placas de Petri.

\subsection{Determinação da coloração Gram}

Para a identificar os diferentes tipos de bactérias que cresceram no meio de cultura, utilizou-se a técnica da coloração Gram, que consiste em corar as bactérias através de agentes químicos específicos (cristal violeta, lugol e safranina), a diferença de coloração se dá de acordo com a composição de suas paredes celulares.

\section{RESULTADOS E DISCUSSÃO}

Todas as instituições consomem água tratada fornecida pelo DAE, exceto a instituição I, que faz uso de um poço artesiano, o qual contribui com a maior parcela de água consumida. Observou-se um fato bastante alarmante, 02 instituições afirmaram que as caixas d'água não passaram por processo de limpeza em um período de mais de 10 anos. As demais informaram um tempo que varia de 02 meses a 05 anos.

\subsection{Análises físico-químicas e microbiológicas}

Os resultados das análises físico-químicas e microbiológicas das amostras das instituições estão representados na Tabela 01. 


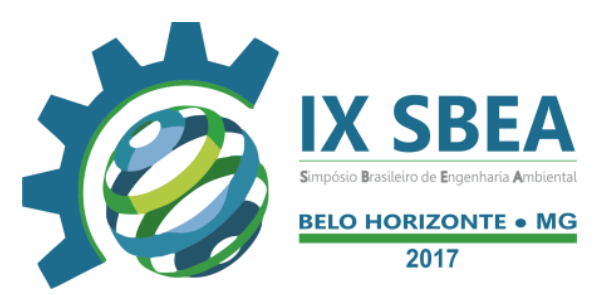

Tabela 01 - Resultados das análises físico-químicas e microbiológicas das amostras dos pontos 1, 2 e 0 das instituições estudadas

\begin{tabular}{|c|c|c|c|c|c|c|c|}
\hline \multirow[b]{2}{*}{ Instituiçãa } & \multirow[b]{2}{*}{ Pontos } & \multicolumn{3}{|c|}{ Análises físico-químicas } & \multicolumn{3}{|c|}{ Análises microbiológicas } \\
\hline & & $\begin{array}{c}\mathrm{pH} \\
(6,0 \text { a } 9,5)^{*}\end{array}$ & $\begin{array}{l}\text { Turbidez } \\
(<5 u T)^{*}\end{array}$ & $\begin{array}{c}\text { Cloro } \\
\text { residual livre } \\
(0,2 \text { a } 2,0 \mathrm{mg} / \mathrm{L})^{*}\end{array}$ & $\begin{array}{l}\text { Coliformes totais } \\
\text { (ausência em 100mL)* }\end{array}$ & $\begin{array}{c}\text { E. coli } \\
\text { (ausência em } 100 m L \text { )* }\end{array}$ & $\begin{array}{c}\text { Bactérias } \\
\text { heterotróficas } \\
\text { (até } 500 U F C / m L) *\end{array}$ \\
\hline \multirow{3}{*}{$\mathbf{A}$} & 1 & 6,09 & 0,51 & 0 & A & A & 0 \\
\hline & 2 & 6,10 & 1,27 & 1,06 & A & A & 10 \\
\hline & 0 & 6,03 & 1,37 & 1,41 & A & A & 46 \\
\hline \multirow{3}{*}{ B } & 1 & 6,07 & 0,65 & 0 & $P$ & A & 4 \\
\hline & 2 & 6,11 & 0,49 & 1,06 & A & A & 1 \\
\hline & 0 & 6,11 & 0,66 & 1,41 & A & A & 110 \\
\hline \multirow{3}{*}{$\mathbf{C}$} & 1 & 6,05 & 0,52 & 0 & A & A & 1 \\
\hline & 2 & 6,05 & 0,40 & 1,41 & A & A & 15 \\
\hline & 0 & 6,00 & 1,39 & 1,77 & A & A & 1 \\
\hline \multirow{3}{*}{ D } & 1 & 6,06 & 0,47 & 0 & $\mathrm{P}$ & A & 68 \\
\hline & 2 & 6,07 & 0,46 & 0,71 & A & A & 43 \\
\hline & 0 & 6,12 & 0,55 & 1,06 & A & A & 1 \\
\hline \multirow{3}{*}{$\mathbf{E}$} & 1 & 6,14 & 0,45 & 0,35 & A & A & 44 \\
\hline & 2 & 6,06 & 0,59 & 0,35 & A & A & 36 \\
\hline & 0 & 6,18 & 0,67 & 0,71 & A & A & 7 \\
\hline
\end{tabular}




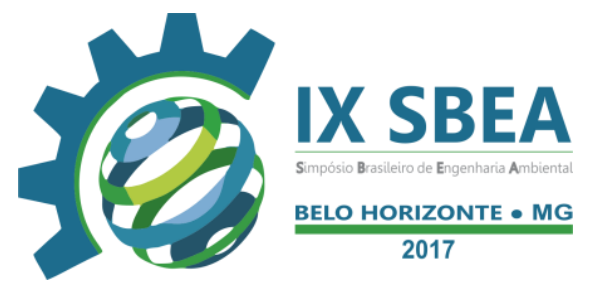

(continuação)

\begin{tabular}{|c|c|c|c|c|c|c|c|}
\hline \multirow[b]{2}{*}{ Instituição } & \multirow[b]{2}{*}{ Pontos } & \multicolumn{3}{|c|}{ Análises físico-químicas } & \multicolumn{3}{|c|}{ Análises microbiológicas } \\
\hline & & $\begin{array}{c}\mathrm{pH} \\
(6,0 \text { a } 9,5)^{*}\end{array}$ & $\begin{array}{l}\text { Turbidez } \\
(<5 u T)^{*}\end{array}$ & $\begin{array}{c}\text { Cloro } \\
\text { residual livre } \\
(0,2 \text { a } 2,0 \mathrm{mg} / \mathrm{L})^{*}\end{array}$ & $\begin{array}{c}\text { Coliformes totais } \\
\text { (ausência em } 100 \mathrm{~mL})^{*}\end{array}$ & $\begin{array}{c}\text { E. coli } \\
\text { (ausência em } 100 \mathrm{~mL})^{*}\end{array}$ & $\begin{array}{c}\text { Bactérias } \\
\text { heterotróficas } \\
\text { (até } 500 U F C / m L) *\end{array}$ \\
\hline \multirow{3}{*}{$\mathbf{F}$} & 1 & 6,18 & 0,66 & 0 & A & A & 11 \\
\hline & 2 & 6,20 & 0,68 & 0,71 & $\mathrm{~A}$ & A & 217 \\
\hline & 0 & 6,03 & 0,47 & 1,06 & A & A & 3 \\
\hline \multirow{3}{*}{ G } & 1 & 6,20 & 0,39 & 0 & A & A & 1 \\
\hline & 2 & 6,24 & 0,49 & 0,71 & A & A & 2 \\
\hline & 0 & 6,17 & 0,23 & 1,06 & A & A & 2 \\
\hline \multirow{3}{*}{$\mathbf{H}$} & 1 & 6,25 & 0,56 & 0 & A & A & 3 \\
\hline & 2 & 6,21 & 0,97 & 0,71 & A & A & 6 \\
\hline & 0 & 6,28 & 0,28 & 1,06 & A & A & 50 \\
\hline \multirow{3}{*}{ I } & 1 & 6,33 & 0,23 & 0 & A & A & 254 \\
\hline & 2 & 6,40 & 0,26 & 0 & A & A & 442 \\
\hline & 0 & NR & NR & NR & NR & NR & NR \\
\hline
\end{tabular}

Fonte: Pesquisa aplicada, 2016.

Legenda: $A$ a I= códigos das instituições das quais as amostras de água foram coletadas

$1=$ bebedouro; $2=$ torneira da cozinha; $0=$ entrada da rede de água

$\mathrm{NR}=$ análise não realizada devido à impossibilidade de coleta de amostras no Ponto 0

$\mathrm{P}=$ presença; $\mathrm{A}=$ ausência

Nota: *valores de referência estabelecidos pela Portaria No2.914/11 do Ministério da Saúde. 


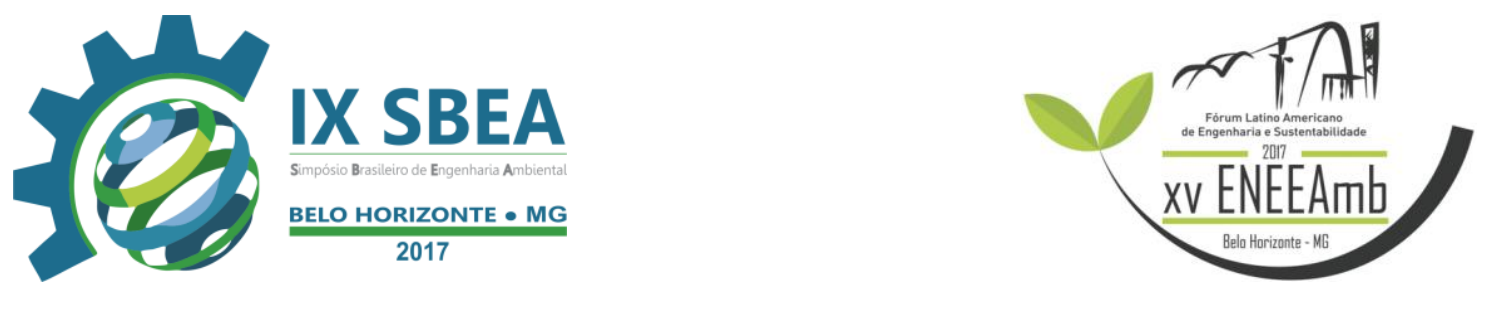

Os resultados dos parâmetros pH e turbidez, em todos os pontos amostrados, satisfizeram os limites estabelecidos na Portaria $\mathrm{N}^{\mathrm{o}}$ 2.914/11: 6,0 a 9,5 para o $\mathrm{pH}$, e valores menores que 5 uT para a turbidez. Em relação ao parâmetro cloro residual livre, 08 das 09 instituições estudadas, apresentaram resultado fora do padrão estabelecido na legislação, onde o limite de concentração entre 0,2 a 2,0mg/L de cloro residual livre na água. A maior parte desses resultados fora do padrão ocorreram nos bebedouros (Ponto 1) das instituições, os quais apresentaram ausência de cloro residual na água (concentração de $0 \mathrm{mg} / \mathrm{L}$ ); apenas a instituição I apresentou ausência de cloro residual no Ponto 2 (torneira da cozinha), tendo apresentado ausência também no Ponto 1. Todas as amostras coletadas no Ponto 0 (entrada da rede de água) se apresentaram adequadas aos limites de cloro estabelecidos na legislação. Chegou-se à conclusão de que a água das instituições, em quase sua totalidade, não atendeu aos parâmetros físico-químicos exigidos pela Portaria $N^{o} 2.914 / 11$, visto que $88,88 \%$ das instituições não atenderam ao padrão de concentração de cloro residual livre.

As análises microbiológicas mostraram resultados positivos para presença de coliformes totais apenas nas amostras do Ponto 1 (bebedouro) das instituições B e D. Porém, não foi detectada presença de E. coli nessas amostras a partir da exposição das mesmas à luz ultravioleta (Figura 15). 

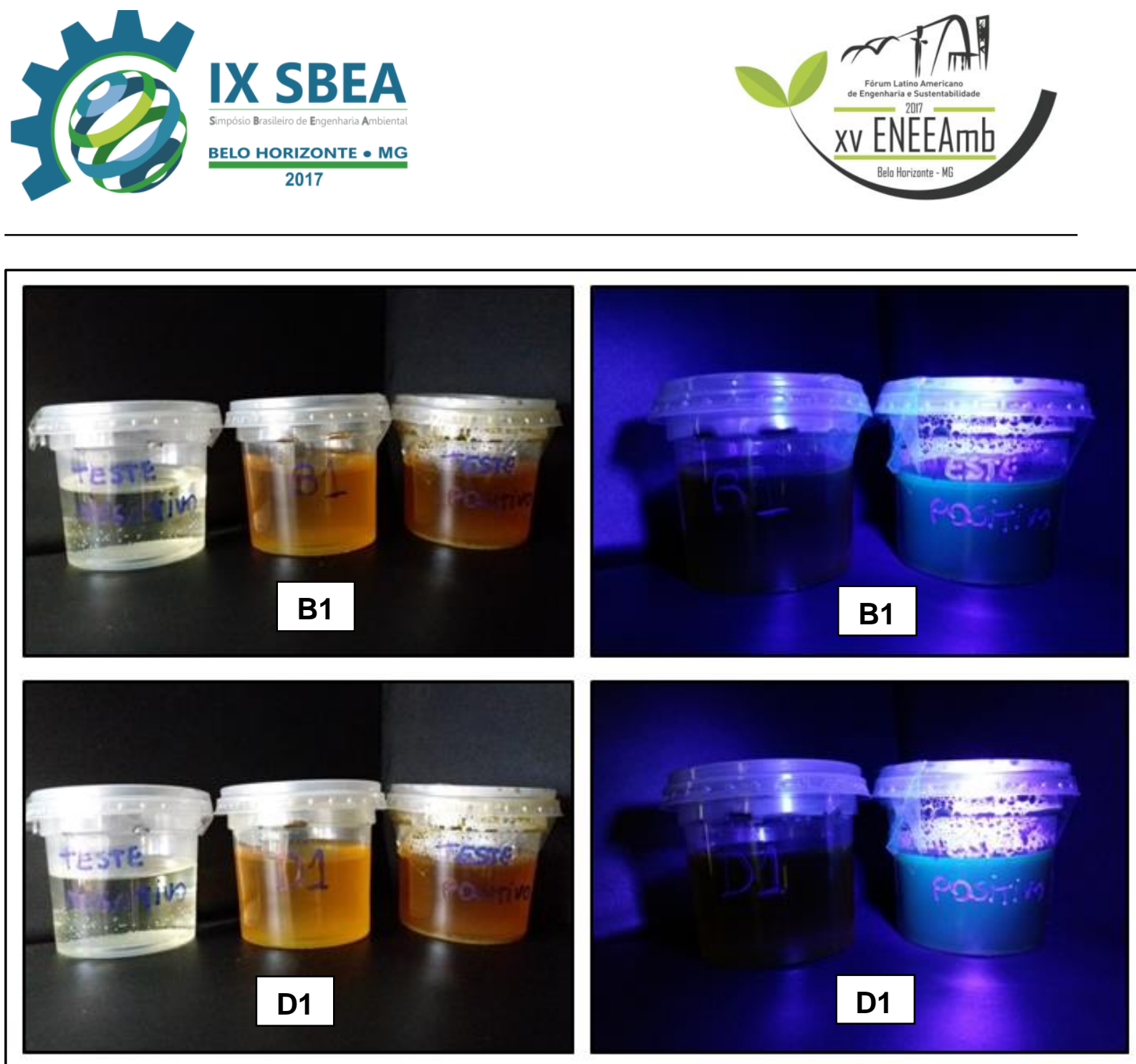

Figura 15 - Resultados positivos para presença de coliformes totais e resultados negativos para presença de E. coli nas amostras do Ponto 1 (bebedouro) das instituições

$$
\text { B e D }
$$

Fonte: Pesquisa documental, 2016.

Conforme Anexo I da Portaria No 2.914/11, admite-se a presença de coliformes totais em apenas 01 amostra mensal para sistemas ou soluções coletivas que abastecem menos de 20.000 habitantes e em 5\% das amostras mensais em sistemas ou soluções coletivas que abastecem mais de 20.000 habitantes. Diante disso, a equipe executora do trabalho retornará às instituições $\mathrm{B}$ e $\mathrm{D}$ para a realização de novas coletas para conclusão final quanto à situação microbiológica de coliformes totais na água. Ressaltase que a Portaria $\mathrm{N}^{\circ} 2.914 / 11$ determina que não haja presença de Escherichia coli na água para consumo humano, independente do número de amostras analisadas. As demais instituições estudadas obtiveram resultados negativos tanto para a presença de coliformes totais quanto para presença de E. coli em todos os pontos de coleta. 


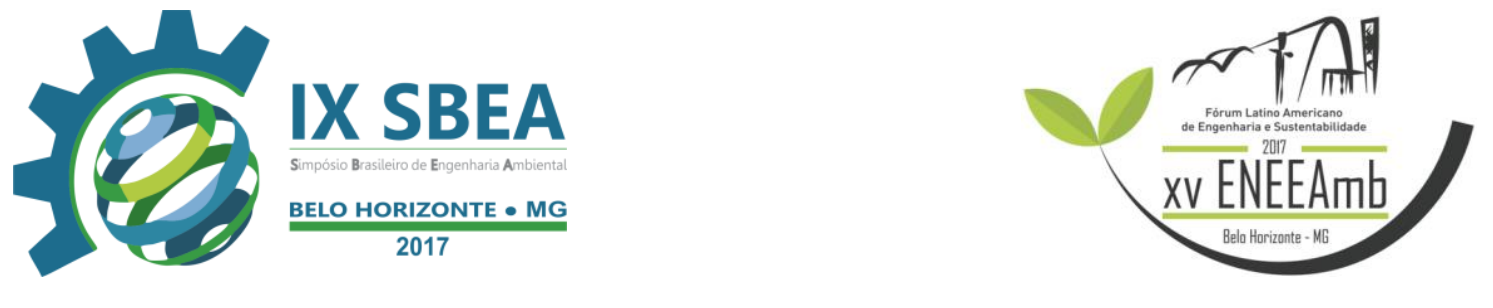

Tendo em vista que todas as amostras do Ponto 0 apresentaram resultado negativo para ausência de coliformes, e baseando-se no estudo feito por Scuracchio (2011), sustenta-se a hipótese de que a contaminação da água, e o consequente comprometimento da sua qualidade, estão ocorrendo nos dispositivos de reservação, os quais, conforme exposto nos questionários aplicados, não possuem uma limpeza periódica adequada. Diante disso, as instituições B e D serão notificadas quanto aos resultados encontrados e lhes serão propostas medidas corretivas para a atual situação.

Os resultados obtidos pela técnica de coloração Gram, para os pontos 1, 2 e 0 de cada instituição conclui-se, que das 26 amostras de água coletadas, 42,3\% tinham a presença de bactérias gram-negativas e 34,6\% gram-positivas.

\section{CONCLUSÕES/RECOMENDAÇÕES}

As características físico-químicas e microbiológicas propostas para análises puderam ser analisadas e comparadas com o padrão estabelecido pela Portaria $\mathrm{N}^{\mathrm{o}}$ 2.914/11. Percebe-se a importância de alertar as instituições e o poder público dos resultados encontrados, pois os mesmos devem providenciar mão-de-obra para a execução da limpeza regular das caixas d'água. Este alerta se torna urgente, visto que os reservatórios de algumas instituições não passam pelo processo de limpeza já por um período de 10 anos, o que abre caminhos para grandes chances de contaminação da água.

\section{REFERÊNCIAS BIBLIOGRÁFICAS}

ANVISA - Agência Nacional de Vigilância Sanitária. Descrição dos meios de cultura empregados nos exames microbiológicos. 2004. Disponível em:

<http://www.anvisa.gov.br/servicosaude/microbiologia/mod_4_2004.pdf >. Acesso em: 05 jun. 2016.

BAIRD, C. Química Ambiental. Porto Alegre: Bookman, 2004. 622p

BRASIL. Ministério da Saúde. Portaria N 2.914 de 12 de dezembro de 2011. Dispõe sobre os procedimentos de controle e de vigilância da qualidade da água para consumo humano e seu padrão de potabilidade. Brasília, DF, 2011. 


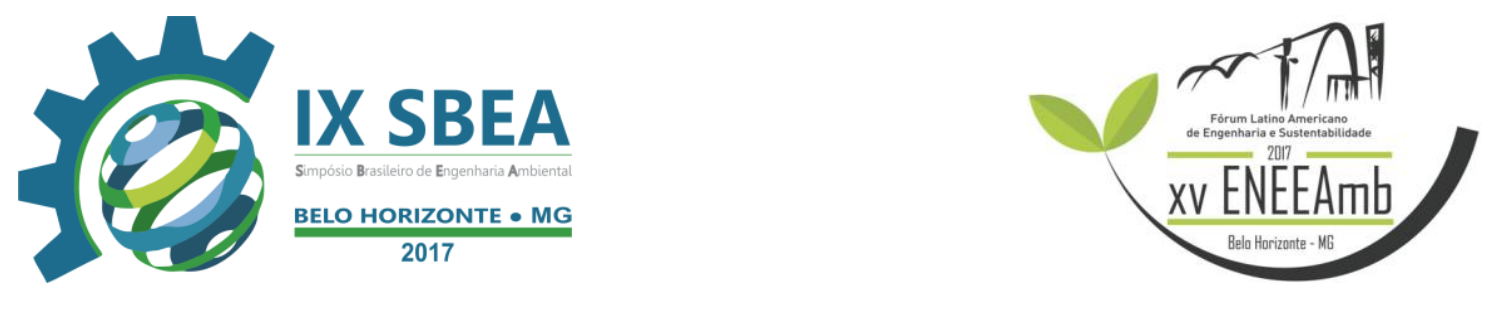

FUNASA - Fundação Nacional de Saúde. Manual prático de análise da água. $4^{\mathrm{a}}$ ed. Brasília: Funasa, 2013. Disponível em: < http://www.funasa.gov.br/site/wpcontent/files_mf/manual_pratico_de_analise_de_agua_2.pdf>. Acesso em: 07 jun. 2016.

MINISTÉRIO DA SAÚDE. Análise de indicadores relacionados à água para consumo humano e doenças de veiculação hídrica no Brasil, ano 2013, utilizando a metodologia da matriz de indicadores da Organização Mundial da Saúde (OMS). Brasília : Ministério da Saúde, 2015. 37 p. Disponível em: $<$ http://u.saude.gov.br/images/pdf/2015/marco/10/analise-indicadores-agua-10mar15web.pdf >. Acesso em: 05 jun. 2016.

SCURACCHIO, Paola Andressa. Qualidade da água utilizada para consumo em escolas no município de São Carlos-SP. 2010. 56 f. Dissertação (mestrado) Universidade Estadual Paulista, Faculdade de Ciências Farmacêuticas, 2010. Disponível em: <http://hdl.handle.net/11449/88588>. Acesso em: 25 mai. 2016.

VON SPERLING, M. Introdução à qualidade das águas e ao tratamento de esgotos. Belo Horizonte: Departamento de Engenharia Sanitária e Ambiental, UFMG, 2005. 240 p. (Princípios do tratamento biológico de águas residuárias, v. 1). 